\title{
Auditory Interfaces and Sonification
}

Michael A. Nees and Bruce N. Walker

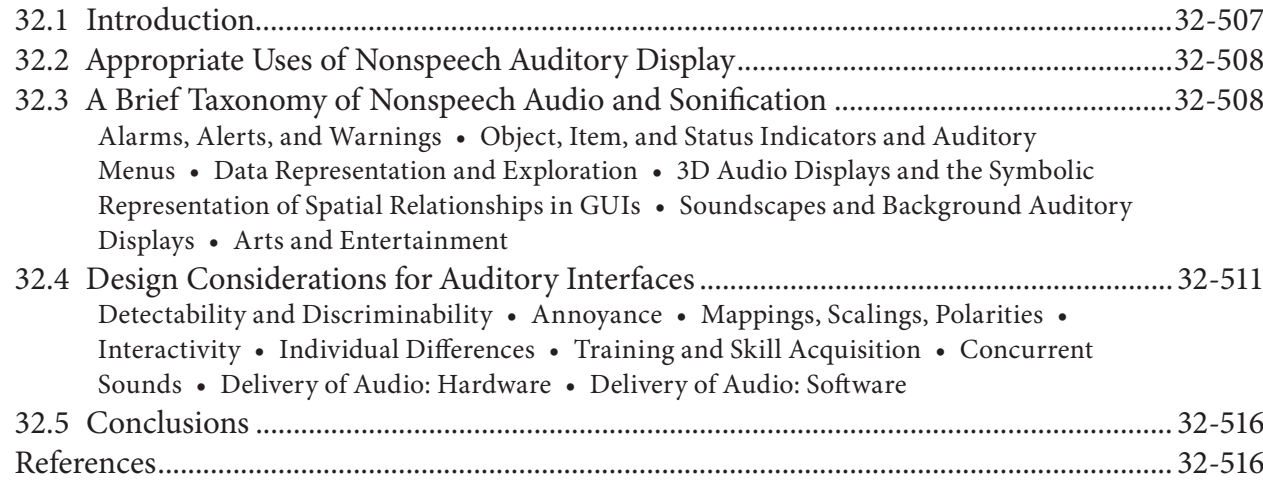

\subsection{Introduction}

Auditory interfaces and sonification-information display by means of nonspeech audio (Kramer et al., 1999) - have been the subject of increasing interest in recent decades (for reviews, see Kramer et al., 1999; Frysinger, 2005). With the advent of ubiquitous digital technologies, high-fidelity sound samples have become increasingly easy and inexpensive to produce and implement (Hereford and Winn, 1994; Flowers, Buhman, and Turnage, 2005). Perhaps more important, however, an increasing awareness of the shortcomings and limitations of traditional visual interfaces has spurred research on sound as a viable mode of information display. Nonspeech audio cues have been implemented to varying degrees in interface design, ranging from nonspeech audio as a complement or supplement to existing visual displays (e.g., Brown, Newsome, and Glinert, 1989; Brewster, 1997), to hybrid systems that integrate nonspeech audio with other audio technologies (e.g., screen readers; see Morley et al., 1999; Stockman, Hind, and Frauenberger, 2005). Attempts have even been made to develop interfaces (usually for the visually impaired) where feedback and interaction are driven primarily by sounds (e.g., Bonebright and Nees, in press; Edwards, 1989a, 1989b; Mynatt, 1997).

Despite the potential utility of sound in interface design, a recent survey of experts in HCI and usability (Frauenberger, Stockman, and Bourguet, 2007a) reported that only about 58\% of respondents had designed with audio in any form. Nonspeech audio and sonification represent an important tool for universally accessible interface design, yet most interface designers consider speech audio first (and perhaps exclusively) when implementing audio in a system. Perhaps as a relic of the limited sound production capabilities of early personal computers (see Flowers, Buhman, and Turnage, 2005), perceptions (and in some cases legitimate concerns) linger that sounds in interfaces are a minimally informative annoyance to the user.

This chapter argues that appropriately chosen and implemented nonspeech sounds can be a pleasant, informative, and integral part of interface design, and interfaces with nonspeech audio can promote adherence to at least five of the seven principles of universal design (Connell et al., 1997; McGuire, Scott, and Shaw, 2006), including (1) equitable use; (2) flexibility in use; (3) simple and intuitive use; (4) perceptible information; and (5) tolerance for error.

The current chapter seeks to provide an introduction to nonspeech auditory information display and an overview of the relevant issues and critical decision points regarding the use of nonspeech audio in interfaces. The discussion is guided by the theme that nonspeech auditory displays can universally enhance the human operator's experience with human-machine systems. As this chapter focuses on the potential benefits of nonspeech audio, the interested reader is referred to other chapters in this volume (e.g., Chapter 28, "Screen Readers," Chapter 30, "Speech Input to Support Universal Access," and Chapter 40, "Contributions of 'Ambient' Multimodality to Universal Access") for a complete discussion of the range of interface options available to the auditory or multimodal display engineer. 


\subsection{Appropriate Uses of Nonspeech Auditory Display}

The best-practice use of nonspeech audio in interfaces requires a careful consideration of the types of users, tasks, and environments where the system will be implemented (for more detailed discussions, see Kramer, 1994; Barrass, 1997; Nees and Walker, 2007). To the extent that nonspeech audio is able to effectively convey the intended message, obvious accessibility benefits are incurred by certain types of system users (i.e., equitable use, see Connell et al., 1997; McGuire et al., 2006), particularly the 161 million people worldwide who are blind or visually impaired (Resnikoff et al., 2004). Screen readers (see Chapter 28, "Screen Readers," in this volume) have been quite effective at making text (and other verbal information) accessible for blind and visually impaired people across a wide variety of digital systems (Tobias, 2003). Other aspects of the interface (e.g., spatial, pictorial, or iconic information, etc.), however, cannot be easily represented with a simple text translation, and the inherent limitations introduced by a text-to-speech display system may introduce new navigation and usability difficulties, especially when the original materials (e.g., web pages, etc.) were not developed with a consideration of screen reader accessibility (Mankoff et al., 2005).

While accessibility for special populations has been one driving force in auditory display research, certain task dependencies and environmental conditions may render the affordances of nonspeech audio beneficial for most users of a system. For example, recent advances in technology have paradoxically expanded the realm of visual information display toward opposite extremes in physical size. Portable devices like cell phones, mp3 players, and even laptop computers continue the trend toward smaller physical dimensions, thereby leaving appreciably less space (or perhaps even no space) for a visual display to occupy (see, e.g., Brewster, 2002). Fixed workstations, on the other hand, have become characterized by multiple visual displays with increasingly large physical sizes, due in part to increases not only in the affordability of displays but also in the expanded computing power to support multiple concurrent displays. As a result, visually intensive workstations and other multitasking situations may overburden the visual modality (Grudin, 2001). System limitations from both small and large visual displays are universally applicable and not unique to any particular type of user, and the inclusion of nonspeech audio in some interfaces can promote universal design principles such as flexibility in use and perceptible information (Connell et al., 1997; McGuire et al., 2006).

In addition to these display-related interface design challenges, environmental conditions external to the system may impose further obstacles for the use of traditional, visual-only displays. Line of sight with a visual display may be obscured (e.g., a firefighter in a smoke-filled room) or unstable (e.g., a jogger viewing an $\mathrm{mp} 3$ player's display). Other task dependencies may introduce additional demands on the human visual system that prevent the concurrent use of a visual display (e.g., when navigating or using mobile devices while walking, driving, or performing any other visually demanding task). Audition requires no physical or stable line-of- sight with a display device (Kramer, 1994), which again allows for equitable use, flexibility in use, and perceptible information, and the inclusion of audio cues may even introduce more tolerance for error (Connell et al., 1997; McGuire et al., 2006) into the system than visual displays alone.

Another notable property of the human auditory system is its sensitivity to the temporal aspects of sound (Bregman, 1990; Kramer, 1994; Flowers and Hauer, 1995; Flowers, Buhman, and Turnage, 1997; Kramer et al., 1999). In many instances, response times for auditory stimuli are faster than those for visual stimuli (Kramer, 1994; Spence and Driver, 1997). Furthermore, people can resolve subtle temporal dynamics in sounds more readily than in visual stimuli, thus the rendering of data into sound may manifest periodic or other temporal information that is not easily perceivable in visualizations (Flowers, Buhman, and Turnage, 2005). Audition, then, may be the most appropriate modality for simple and intuitive (Connell et al., 1997; McGuire et al., 2006) information display when data have complex patterns, express meaningful changes in time, or require immediate action.

\subsection{A Brief Taxonomy of Nonspeech Audio and Sonification}

While nonspeech audio has an important role to play in interface design, the specific types of nonspeech sounds that could be used to solve a given interface design challenge are numerous and diverse. Proposed categorical descriptions of nonspeech sounds generally have been arranged according to form (i.e., according to the parameters of the sound) or function (i.e., with respect to the role of the sound within a system) with some convergence between these approaches. A brief description of the types of nonspeech sounds used in interface design is offered here; for a summary, see Table 32.1. The current discussion is organized roughly according to the functions of sounds in interfaces, but in reality the definitional boundaries for nonspeech audio sounds tend be vague and overlapping. For more discussion on taxonomic descriptions of nonspeech auditory displays, the interested reader is referred to Kramer (1994), Walker and Kramer (2004, 2006a, 2006b), and de Campo (2007), whose sonification design map organized the relationships between nonspeech auditory displays along several quantitative continua.

\subsubsection{Alarms, Alerts, and Warnings}

Alarms, alerts, and warnings are generally brief, infrequent, unsubtle sounds designed to capture a person's attention. Traditionally alerts and warnings convey binary status information about an event's onset or offset (Edworthy and Hellier, 2006). For example, a doorbell informs a dwelling's occupants that someone is at the door (i.e., the alert indicates the onset of an event, the arrival of a visitor); this alert does not indicate who is outside, or what they might want. Alerts and warnings usually convey that immediate (or at least temporally proximal) action is required, and Haas and Edworthy (1996) found that higher 
TABLE 32.1 Common Classes of Auditory Displays with Their Typical Forms and Functions in Systems

\begin{tabular}{lll}
\hline Common Auditory Display Classes & $\begin{array}{l}\text { Typical Forms or Characteristic } \\
\text { Sound Manipulations }\end{array}$ & Common Functions in Systems \\
\hline Alarms & Brief, simple, sounds that capture attention & Alerting, warning \\
Auditory icons & Environmental sounds; ecologically relevant sounds & Object, status, and process indicators; auditory menus \\
Earcons & Brief, abstract motifs with rule-based iterations & Object, status, and process indicators; auditory menus \\
Spearcons & Brief, accelerated speech & Object, status, and process indicators; auditory menus \\
Auditory graphs & Data mapped to frequency & Data exploration aids \\
Audification & Periodic data sampled within audible range drive frequency & Data exploration aids \\
Model-based sonifications & Various & Data exploration aids \\
3-D audio displays & Virtual spatial audio via HRTFs & Spatial-orienting cues; navigation aids \\
Soundscapes & Various, often naturalistic & Ongoing status indicators; monitoring aids \\
Audio in arts and entertainment & Various & Sonification as art; aids for enhanced and accessible \\
\end{tabular}

frequency, rate, and intensity all contribute to more perceived urgency in an auditory alarm signal.

\subsubsection{Object, Item, and Status Indicators and Auditory Menus}

Sounds such as earcons (e.g., Blattner, Sumikawa, and Greenberg, 1989; Brewster, Wright, and Edwards, 1993; Bonebright and Nees, 2007a; McGookin and Brewster, 2004), auditory icons (e.g., Gaver, 1989; Keller and Stevens, 2004; Bonebright and Nees, 2007a), and spearcons (Walker, Nance, and Lindsay, 2006; Palladino and Walker, 2007) are examples of status and process indicators. Like alerts and warnings, these sounds tend to be brief, but they provide informative cues about the nature of the underlying action or event. These sounds are often used to facilitate tasks such as scrolling (Brewster, Wright, and Edward, 1994), pointing, clicking, and dragging with the mouse (Winberg and Hellstrom, 2003), or moving files, and so on, in the interface. Earcons are abstract, artificial sounds that bear no ecological relationship to the represented process or event (e.g., beeps, chimes, abstract sound motives, etc.; see Blattner, Sumikawa, and Greenberg, 1989). Auditory icons are more natural sounds that have some real-world relationship with their referent process or event (Gaver, 1989), although the degree of ecological relatedness may vary (see Keller and Stevens, 2004). The abstract nature of earcons allows for flexibility in representation, as such abstract sounds can be assigned to most any object, item, or process in an interface. A trade-off exists, however, in that the user is required to learn the association between sounds and their referents; for large catalogues of abstract sounds, users may be unwilling or unable to learn the meaning of the sounds (Watson and Kidd, 1994). Research has shown that auditory icons are generally easier to learn and remember than earcons (Bonebright and Nees, 2007a; for a review, also see Edworthy and Hellier, 2006), but auditory icons are less flexible in that some objects, items, and processes have no inherent, ecological sound association (e.g., What sound should represent a Save command?).

Recently, an alternative to earcons and auditory icons has emerged that may be able to ameliorate some of the flexibilitylearnability trade-off in interface sounds. Spearcons use temporally compressed speech to represent objects, items, or processes with sound (Walker, Nance, and Lindsay, 2006; Palladino and Walker, 2007). ${ }^{1}$ Spearcons have been shown to outperform both earcons and auditory icons (Walker, Nance, and Lindsay, 2006) and may be especially useful in the design of flexible auditory menus (Palladino and Walker, 2007) or for representing a large number of items.

\subsubsection{Data Representation and Exploration}

Rather than offering a brief indication of a transitory system state, auditory displays for data exploration use sound to represent information from an entire (usually quantitative) data set. Auditory graphs (for representative work, see Flowers and Hauer, 1992, 1993, 1995; Brown and Brewster, 2003; Smith and Walker, 2005; Nees and Walker, 2007) are typical examples of sonifications designed for data exploration purposes. Auditory graphs most commonly use changes in auditory frequency to correspond to changes in data values along the visual y axis, while time corresponds to the visual $\mathrm{x}$ axis. Nees and Walker (2007) recently proposed a conceptual psychological model of auditory graph comprehension. They argued that the advantages of visual graphs, namely the emergence of otherwise unnoticed patterns and data features in plots of data, can be preserved in auditory representations of quantitative data. In much the same way as individual data points combine to form cohesive patterns in a visual graph, sequences of notes in auditory graphs are grouped according to Gestalt principles and can convey equivalent information (Nees and Walker, 2008).

Exploratory work has also examined auditory versions of numerous traditional display formats, including auditory scatterplots (e.g., Flowers, Buhman, and Turnage, 1997; Bonebright et al., 2001), box-whisker plots (Flowers and Hauer, 1992; Peres and Lane, 2003, 2005), histograms (Flowers and Hauer, 1993), multidimensional data sets (Hermann and Hunt, 2005), and

${ }^{1}$ Whether or not spearcons are recognized by listeners as speech may depend upon the listener's abilities and experience, as well as the word or phrase that is accelerated. As the name implies, spearcons can be viewed as a hybrid of speech and nonspeech auditory displays. 
tabular data (Stockman, Hind, and Frauenberger, 2005). These efforts have commonly relied on variations of the pitch-time display format described previously, and the variety of displays that have been developed suggest auditory analogues or alternatives for many visual graphical displays. Audification, for example, shifts the waveforms of periodic data into the audible range of frequencies for data exploration (e.g., seismographs; see Dombois, 2001), while model-based sonifications represent multidimensional data sets as virtual, interactive objects that systematically drive sound via user input (see Section 32.4.4; Hermann and Hunt, 2005).

As an alternative to traditional visualizations, auditory displays of quantitative information may: (1) make data accessible for visually impaired students and scientists, thereby promoting collaborative efforts; (2) provide an immersive, multimodal, and more effective educational experience for students of math and science; (3) allow for the detection of otherwise unnoticed patterns and anomalies in data; and (4) offer an equivalent, alternative mode of information display in circumstances where visual information display is inadequate (see, e.g., Kramer, 1994; Kramer et al., 1999; Nees and Walker, 2007). These advantages epitomize the spirit and principles of universal design (Connell et al., 1997; McGuire et al., 2006).

\subsubsection{D Audio Displays and the Symbolic Representation of Spatial Relationships in GUIs}

A number of studies have confirmed that auditory signals can direct visual attention to a spatial location (e.g., Mondor and Amirault, 1998; McDonald, Teder-Salejarvi, and Hillyard, 2000; Eimer, 2001; Brock, Stroup, and Ballas, 2002; see also Schmitt, Postma, and De Haan, 2000; Spence, McDonald, and Driver, 2004), and spatial manipulations of audio have been shown to facilitate a three-dimensional visual search (Bolia, D'Angelo, and McKinley, 1999). Thus, spatial audio has been recognized as an important means of capturing, orienting, or guiding attention (Kramer, 1994). Current technology allows for the delivery of $3 D$ or virtual spatial audio: a two-point sound source (e.g., headphones) in conjunction with head-related transfer functions (HRTFs) can induce the perception that a sound originated from an external environmental source (Wightman and Kistler, 1983, 1989; Walker and Lindsay, 2005; Folds, 2006).

In addition to orienting applications, virtual spatial audio cues have been successfully implemented as audio-only navigational aids, where the virtual spatial location of an audio beacon guides the user along a specified path to a destination. ${ }^{2}$ Examples of this approach include the system for wearable audio

\footnotetext{
${ }^{2}$ Virtual spatial audio cues seem particularly suited to indicate where an operator should look or move in physical space. It should be noted, however, that attempts to map virtual audio-spatial location to nonspatial data (e.g., using stereo panning and higher or lower virtual spatial elevation to represent quantities for conceptual dimensions, etc.; see Roth et al., 2002) have been less successful, perhaps owing to systematic misperceptions of virtual elevation (see Folds, 2006).
}

navigation (SWAN; Walker and Lindsay, 2005; Wilson et al., 2007), and the personal guidance system (PGS; Golledge et al., 1991; Loomis, Golledge, and Klatzky, 1993; Loomis et al., 2005). The SWAN system generally employs spatialized nonspeech sounds, whereas the PGS has usually used spatialized speech.

Walker and Lindsay tested a number of different types of audio beacons, including pink noise bursts (i.e., broad-spectrum noise bursts with equal power per octave), a sonar-like ping, and pure tones, and the broad-spectrum pink noise cue was found to be particularly effective for guiding navigation (Walker and Lindsay, 2006a, 2006b). While a wealth of data support the feasibility of nonspeech audio as a navigation aid, it should be noted that performance outcomes for navigation were negatively impacted by the introduction of a (particularly difficult) concurrent speech discrimination secondary task (Walker and Lindsay, 2006a). The practical cost of these laboratory-induced performance decrements for the dual-task are unclear, and more research is needed to clarify how competing auditory signals may or may not result in interference for navigation systems and indeed all auditory displays (see Section 32.4.7).

While spatial audio has been shown to effectively direct attention and guide navigation through physical space on a gross, or macro-level (e.g., from upwards of several inches), much research has been directed at the representation of spatial relationships with sound for smaller physical spaces, such as the dimensions (i.e., the screen size) of traditional visual displays. For example, lateralized audio (e.g., left-right stereo panning) has been used in conjunction with frequency cues (with higher frequency corresponding to higher spatial position) to provide auditory representations of the spatial relationships between objects on a computer screen (Winberg and Hellstrom, 2003). Other interfaces have used increasing pitch to represent movement from left to right and up and down on the screen (Edwards, 1989b), while yet other approaches have used combinations of pitch manipulations and the number of sounds presented to indicate position within a grid of rows and columns on a computer display (Bonebright and Nees, in press). Some of these projects have been targeted at visually impaired users; some have specifically targeted sighted users. Nevertheless, the approaches are inherently universal in that they promote alternative and flexible means of interaction with interfaces for many users.

Despite the insights gained from such studies, there remains no inherent, standard, or even clearly best way to use sound to convey the spatial relationships between objects in user interfaces. A major design dilemma, then, involves the extent to which audio interfaces should maintain the conventions of visual interfaces (Mynatt and Edwards, 1992), and indeed most attempts at auditory display seek to emulate or translate elements of visual interfaces to the auditory modality. While retrofitting visual interfaces with sound can offer some consistencies across modalities, the constraints of this approach may hinder the design of auditory interfaces, and native auditory interfaces would likely sound much different from interfaces designed with a relative visual counterpart in mind. While visual objects exist primarily in space, auditory stimuli occur in time. A more appropriate 
approach to auditory interface design, therefore, may require designers to focus more strictly on auditory capabilities. Such interfaces may present the items and objects of the interface in a fast, linear fashion over time (see, e.g., Eiriksdottir et al., 2006) rather than attempting to provide auditory versions of the spatial relationships found in visual interfaces. This approach can often lead to the deployment of enhanced auditory menus with a mix of speech and nonspeech components. Such advanced interfaces are relatively novel (compared to simpler text-to-speech menus). Ongoing research in advanced auditory menu-based interfaces looks promising, and will generally provide better interfaces for most users (Yalla and Walker, 2007).

\subsubsection{Soundscapes and Background Auditory Displays}

Many continuous auditory stimuli can be allowed to fade to the extreme periphery of conscious awareness, yet meaningful changes in such ongoing sounds are still noticed (Kramer, 1994). Designers have taken advantage of this auditory capability with soundscapes-ambient, continuous sonifications-to facilitate a human operator's awareness of dynamic scenarios (e.g., a bottling plant, Gaver, Smith, and O'Shea, 1991; financial data, Mauney and Walker, 2004; a crystal factory, Walker and Kramer, 2005). Soundscapes often have been designed to mimic natural, ongoing auditory stimuli (e.g., a thunderstorm with rain), and parameters of the soundscape are mapped to particular variables in a multidimensional data set (e.g., B. S. Mauney and Walker, 2004). While the listener may not necessarily act upon every change in the soundscape, the display allows for ongoing monitoring and awareness of a changing situation.

\subsubsection{Arts and Entertainment}

Researchers and musicians have long recognized the potentially unique aesthetic or entertainment value of data-driven (i.e., sonified) music $^{3}$ (see, e.g., Quinn and Meeker, 2001), and the International Conference on Auditory Display has regularly featured a concert performance (e.g., International Conference on Auditory Display, 2004, 2006). A recent push in research, however, has taken the notion of sonification as entertainment a step further by advocating for enhanced and accessible exhibitions (e.g., museums, aquaria, zoos, etc.). People with disabilities, particularly the visually impaired, have been shut out of many of the educational and entertainment ("edutainment") experiences offered at traditional exhibitions. While virtual, online-accessible museums are one possible solution to the problem (see Anable and Alonzo, 2001), a remote virtual experience lacks many important aspects (including the novelty and excitement) of a live visit to the actual sites of educational and culturally meaningful exhibitions. While recommendations for real museum accessibility are available (Salmen, 1998), the audio component of accessibility has primarily involved text-to-

\footnotetext{
3 Also see http://www.tomdukich.com/weather\%20songs.html.
}

speech conversions of plaques and verbal materials-a practice that does not capture the most interesting aspects of dynamic exhibitions.

Walker and colleagues (Walker et al., 2006; Walker, Kim, and Pendse, 2007) have recently begun developing a system for sonifying the real-time dynamics of an aquarium. The movements of the fish are tracked (e.g., with computer vision) and translated to continuous, nonspeech (and often musical) auditory representations. The result is a soundscape whereby categorical information about the types of fish can, for example, be represented by instruments of different timbre, while movements of the fish can be conveyed by other dimensions of sound such as pitch, tempo, loudness, or spatial location. Similar innovative approaches may enhance the experience of both static and dynamic exhibitions for many users, as supplementary audio may provide for a more immersive environment in museums, zoos, and aquaria where line-of-sight contact with the exhibit may be obscured by crowds or by perceptual or mobility impairments.

Another important development in accessible entertainment has been an increased interest in auditory games (also see Chapter 17, "Designing Universally Accessible Games"). Audio-only interfaces have been developed for traditionally visual games such as the "Towers of Hanoi" (Winberg and Hellstrom, 2001) and "Tic-Tac-Toe" (Targett and Fernstrom, 2003). More elaborate attempts at audio-only gaming have also begun to appear, including an auditory role-playing game based on the Beowulf story (Liljedahl, Papworth, and Lindberg, 2007). Liljedahl et al. argue that audio-only gaming offers players the opportunity to construct rich, unconstrained internal images of the game's landscape from the suggestive nature of the sounds. Interestingly, a recent prototype for an audio-only computer soccer game may actually be able to offer constructive insights for both blind and sighted players on the real soccer field (Stockman et al., 2007).

\subsection{Design Considerations for Auditory Interfaces}

Theoretical accounts of human interactions with sonification and other nonspeech auditory display design have been slow to develop, in part due to the highly interdisciplinary nature of the field (Nees and Walker, 2007). Recently, however, a number of authors have taken steps toward elaborating sonification theory and organizing the extant knowledge base, including de Campo's sonification design space map (de Campo, 2007), Frauenberger, Stockman, and Bourguet's audio design survey (2007a) and framework (2007b), and Nees and Walker's model of auditory graph comprehension (2007). Despite these recent advances in the field, concrete and specific sonification design guidelines that are grounded in literature and theory are still not generally available. While researchers have described guidelines for nonspeech auditory displays (Hereford and Winn, 1994; Watson and Kidd, 1994; Brown et al., 2003; Flowers, 2005; Edworthy and Hellier, 2006), these attempts have generally provided advice for particular instantiations of auditory displays as opposed to 
generalized recommendations or comprehensive descriptions for the entire scope of nonspeech audio. Furthermore, in at least one case it has been shown that adherence to published standards for auditory displays did not even ensure the identifiability of sounds (see Lacherez, Seah, and Sanderson, 2007). Rather than articulating what would necessarily be an incomplete list of rules or guidelines here, this chapter offers a broader discussion of the critical issues for implementing nonspeech audio in interface design. Careful consideration of these topics will help to ensure the appropriate deployment of sound in a system and offer a universally accessible and enhanced interface experience for many populations of users.

\subsubsection{Detectability and Discriminability}

An auditory display is useless if the listener cannot hear the sounds in the system's environment of operation. Research in psychoacoustics has provided ample descriptions of minimum thresholds for detection of sounds along a number of relevant auditory dimensions (e.g., Hartmann, 1997), while masking theories have made valuable predictions about the human listener's ability to hear a sound signal against noise (for a discussion, see Watson and Kidd, 1994). The highly controlled testing conditions for such stimuli, however, can be drastically different from the environments where auditory displays will actually be used by listeners. Accordingly, ecologically plausible testing conditions for applications of auditory displays have been recommended (Watson and Kidd, 1994; Brewster, 2002; see also Walker and Kramer, 2004). Another concern is central or informational masking, whereby sounds are masked at higher levels beyond the cochlea in the auditory system. This variety of masking is not well understood, nor can it readily be predicted by extant models of the acoustic periphery (see Durlach et al., 2003). While the requirement of detectability for auditory information may seem straightforward, the interface designer may encounter problems if simple detection is not given due consideration during the design process.

Given that a sound can be heard by the human listener in the system's environment of operation, a second basic consideration is the discriminability of sounds with distinct meanings in the interface. Like detection, researchers have studied the discriminability of sounds along a wealth of dimensions such as pitch (e.g., Stevens, Volkmann, and Newman, 1937; Turnbull, 1944), loudness (e.g., Stevens, 1936), tempo (e.g., Boltz, 1998), and duration (e.g., Jeon and Fricke, 1997), to name but a few. Again, however, the stimuli and controlled conditions for data collection in such studies may not precisely translate to the realworld scenarios where auditory interfaces will be used, and the designer is cautioned to proceed with an awareness of both the psychoacoustic discriminability of manipulated dimensions of sounds as well as the further additional constraints imposed by the tasks and environments for which the system is designed. Two sounds that carry different pieces of information must be distinguished to ensure that the operator will perceive the intended message.

\subsubsection{Annoyance}

The potential for sounds to annoy the user is a concern for auditory interface design (Frauenberger, Stockman, and Bourguet, 2007b; Kramer, 1994). Edworthy (1998) described the independent nature of sound aesthetics and performance outcomes. Sounds that annoy the user may be ignored or turned off, even when the presence of auditory cues enhances user performance with the system. Likewise, sounds may enhance the aesthetic experience of an interface without improving performance with the system. Some have suggested that musical nonspeech sounds (e.g., sounds from the MIDI instrument base) with their richer harmonic and acoustic features, are easier to perceive than pure tones and simple waveform sounds (Ramloll et al., 2001; Brown et al., 2003; Childs, 2005). Simply using musical sounds, however, will not guarantee a pleasant experience of the auditory interface for all users, tasks, and environments. Bonebright and Nees (in press) recently found that four different types of earcons (including both pitched musical instruments and pure-tonebased variations) as well as a speech condition all led to auditory displays that were rated as "neutral" to somewhat "annoying" in the context of the study task, which was a dual-task listening and orienting paradigm. Another study found that high-pitched interface sounds can be particularly annoying (Bonebright and Nees, 2007a). This makes it clear that developing an auditory interface is, in all regards, a design task, with all the inherent difficulties associated with design. It is encouraging, however, that other research has shown that users can be very satisfied with abstract, nonspeech sounds similar to those used by Bonebright and Nees (e.g., Morley et al., 1999).

In general, very little research has addressed the role of aesthetics in auditory display design and many questions remain regarding how to make aesthetically pleasing interface sounds. It remains advisable to pilot sounds with a representative sample of the target user group to eliminate particularly annoying and displeasing sounds, unless such sounds are invoked with a specific intent (e.g., as an alarm tied to a critical, rare event, etc.). Another possible solution involves customizability, where users are given a choice of instruments or sound types, all of which can convey equivalent information. Regardless of the approach, evaluation of aesthetics needs to be longitudinal, since preferences can evolve, and acceptance can increase or decrease as the user becomes more familiar with the interface.

\subsubsection{Mappings, Scalings, Polarities}

Mapping refers to the dimension of sound that is employed to vary with and thus represent changes in data. For example, an auditory display of temperature could map changes in data to changes in a number of acoustic parameters, such as pitch, loudness, or tempo. In general, groups of listeners have shown some concurrence about which aspects of sound are good for portraying certain conceptual dimensions of data. Nees and Walker (2007) give a detailed discussion and justification of the convention of mapping pitch to $y$-axis spatial location in auditory 
graphs, and pitch generally offers a robust mapping dimension for quantities (Brown et al., 2003; Flowers, 2005). Some sound dimensions (e.g., loudness) are often not very effective representations of data for both perceptual and practical reasons (Neuhoff, Kramer, and Wayand, 2002; Walker and Kramer, 2004). Walker has attempted to determine the appropriate acoustic dimension for a given type of data by examining mappings between numerous conceptual data dimensions (e.g., temperature, pressure, danger) and three acoustic dimensions (pitch, tempo, and spectral brightness; Walker, 2002, 2007). Pitch, for example, generally maps well to changes in temperature, but tempo is not particularly effective for this conceptual dimension. Future research should extend and expand upon this approach to guide interface designers toward best-practice mapping choices. Currently, designers should be warned that not all acoustic mappings are equally effective for representing a given conceptual data dimension, and best-practice design decisions for interfaces will arise from an awareness of empirical data and usability pilot testing. As auditory display design requires explicit decisions regarding mapping, a variety of sources should be consulted to attain an awareness of the varieties of mappings available for nonspeech auditory display designers (e.g., Bonebright et al., 2001; Neuhoff, Kramer, and Wayand, 2002; Walker, 2002, 2007; Brown et al., 2003; Edworthy et al., 2004; Flowers, 2005). Redundant or dual mappings (i.e., mapping more than one acoustic dimension to changes in data) may further facilitate comprehension of the display (Kramer, 1994; Bonebright and Nees, 2007a).

Following the selection of an acoustic mapping for data, the polarity of the data-to-display relationship must be considered. Increases in a given acoustic dimension (e.g., pitch, tempo, etc.) are most often mapped to increases in the data represented (a positive mapping polarity; Walker, 2002, 2007), but listeners agree that some conceptual data dimensions are better represented with a negative polarity mapping. For example, listeners might agree that increasing pitch suggests increasing temperature, yet the same group of listeners may feel that decreasing pitch offers a more intuitive representation of increasing size. Walker and Lane (2001) showed that some polarity mappings were reversed for visually impaired as compared to sighted listeners. While positive polarities may generally capture listener intuitions (Brown et al., 2003), interface designers should be mindful of user populations and conceptual data dimensions for which this convention is violated. Walker $(2002,2007)$ provided data for the preferred polarities for many conceptual data dimensions, and usability testing is advisable when evidence regarding a specific polarity relationship is not available.

Along with polarity, the auditory display designer must also consider the amount of change in an acoustic dimension that will be used to represent a unit of change in the data. Magnitude estimation has been employed to describe the intuitive slopes for scaling frequency to a number of conceptual data dimensions (Walker, 2002, 2007), and the conceptual data dimension being represented impacts the choice of scaling factor in the display. For example, equal quantitative changes (e.g., a one-unit increase) in different conceptual data dimensions (e.g., temperature and size) are not necessarily best represented by the same change in the acoustic display dimension. A match between the listener's preferred or intuitive internal scaling function and the display's scaling function may facilitate comprehension of the information presented, particularly when judgments of absolute or exact values are required. Where feasible, scaling factors should be chosen to match the intuitive user preferences for representing change in a given conceptual dimension (for a number of empirically determined scaling slopes, see Walker, 2002, 2007). Brown et al. (2003) have further suggested minimum (MIDI note 35, $\sim 61.7 \mathrm{~Hz}$ ) and maximum (MIDI note 100, 2637 Hz) scaling anchors. Again, the interface designer is encouraged to consult available empirical data as guidance, but ultimately empirical findings, design experience and expertise, and usability pilot testing will converge to determine the best-practice for a given application.

\subsubsection{Interactivity}

Interfaces for different scenarios may vary considerably in the degree to which interactivity is allowed or encouraged. Some auditory interfaces, such as alarms, may simply be activated by a particular system condition and occur without any opportunity for the user to actively adjust or manipulate the display; noninteractive sounds in interfaces have been referred to as tour based (Franklin and Roberts, 2004) or concert mode (Walker and Kramer, 1996). Other auditory components of an interface may allow for a particular sound message to be replayed, which may often be appropriate given the transient nature of sound. Displays at the extreme end of the interactivity spectrum may allow for elaborate user control of and immersion in the display, including pausing, scanning, scrubbing, skipping backward and forward, and zooming in and out of display dimensions. Such interactivity, called query based (Franklin and Roberts, 2004) or conversation mode (Walker and Kramer, 1996), may be especially helpful for tasks involving data exploration and analysis (see Brown, Brewster, and Riedel, 2002). For model-based sonifications, user control is imperative and drives the presentation of sounds in an entirely active data exploration process (see Hermann and Hunt, 2005). The inclusion of interactive control over the auditory components of a system warrants a consideration of the role of audio in the system and the extent to which such features aid the user in the task at hand versus the cost and potential negative effects of building interactive control into the interface. Of course, the controls that enable this interactivity should also be designed to support universal access (see, e.g., Chapter 29, "Virtual Mouse and Keyboard for Text Entry," and Chapter 33, "Haptic Interaction," in this volume).

\subsubsection{Individual Differences}

Important individual differences may influence the interpretation of auditory displays such that different users may interpret the same sounds to have different meanings. If a technology strives toward universal access, the interface designer should 
be aware of the range and variety of individual differences that must be accommodated (e.g., Meyer and Rose, 2000). For universal design, then, individual differences represent not only a crucially important design challenge, but also an opportunity to meet the needs of diverse populations of users. Individual difference variables that may be relevant to the interpretation of auditory displays include cognitive abilities (e.g., memory and attention), musical ability, listening skills, learning styles, and perceptual abilities. As discussed in the following, researchers have only just begun to examine the role of these individual difference variables in the comprehension of auditory displays. It is also important to note that researchers have yet to consider potential cultural influences on the interpretation of auditory displays or sounds in general, and these types of studies could provide valuable and heretofore lacking insight regarding crosscultural differences or similarities in meaning-making for sounds.

Walker and Lane (2001) found differences between groups of visually impaired and sighted listeners in magnitude estimation tasks. As mentioned previously, this study indicated that in some situations visually impaired and sighted listeners intuit the same polarities for data-to-display mappings, but in other cases different polarities result. Sighted individuals, for example, preferred a positive polarity when mapping frequency to the conceptual dimension "number of dollars," whereas visually impaired individuals preferred a negative polarity. Auditory interface designers must empirically examine and anticipate these potential conflicting intuitions across user groups and take caution against unknowingly creating a display that is biased against universal access.

Researchers have further suggested that the transient nature of auditory displays may impose inordinate burdens on memory (Frauenberger, Stockman, and Bourguet, 2007b; Morley et al., 1999), a concern that warrants a consideration of the impact of cognitive abilities (e.g., memory, attention, etc.) on auditory display performance. Walker and Mauney (2004) studied the impact of individual differences in cognitive abilities on auditory magnitude estimation tasks. They found some evidence that cognitive abilities affected the interpretation of auditory displays. Listeners with better scores on working memory capacity (WMC) and nonverbal reasoning measures performed better on the magnitude estimation task than those listeners who had lower scores on WMC and nonverbal reasoning tests; however, the scaling slope of the data-to-display mappings did not seem to be affected by cognitive abilities, musical experience, or demographic variables (Walker and Mauney, 2004). Mauney (2006) investigated cognitive abilities and musical experience as predictors of frequency and tempo discrimination. Participants completed the Operation span (O-span) task as a measure of working memory capacity and the Raven's progressive matrices task as a measure of nonverbal reasoning. Results showed that performance on the Raven's and O-span tests seemed to predict some, but not all, tested frequency and tempo discrimination thresholds, with better cognitive abilities associated with lower thresholds. As this pattern of results suggested, the role of cognitive abilities in the comprehension of auditory displays is not well understood, although there is reason to believe that further research will yield stable relationships between certain cognitive abilities and performance with auditory stimuli. The generally transient nature of auditory displays may impose memory demands that could exacerbate individual differences in cognitive variables, so good auditory interface design will require the intuitive use of audio that does not require memorization of large catalogues of sounds.

Researchers have long predicted that the special training and listening abilities of musicians would translate to superior performance with auditory displays as compared to nonmusicians, and a few studies have found such a relationship (e.g., Neuhoff, Kramer, and Wayand, 2002; Sandor and Lane, 2003; Lacherez, Seah, and Sanderson, 2007). In general, however, many researchers have reported weak to nonexistent relationships between musical experience and performance with auditory displays (see Watson and Kidd, 1994; Bonebright et al., 2001; Walker, 2002; Nees and Walker, in press). Watson and Kidd (1994) suggested that the comprehension of auditory displays may simply require perceptual acuity (as opposed to musical ability per se), which is likely a variable that is distributed homogeneously across musicians and nonmusicians. Furthermore, while nonmusicians may not be formally trained in music theory, most adult listeners have at least acquired a wealth of implicit knowledge about the rules, structures, and relationships between sounds in music (Bigand, 1993). This implicit knowledge may be enough to perform tasks with auditory interfaces, which generally require no responses related to explicit musical knowledge. Finally, no brief, valid tools exist for measuring musical ability, and the use of surrogate measures (e.g., self-reported years of musical experience) may not be capturing enough of the variance in actual musical ability to detect meaningful relationships (Nees and Walker, 2007).

\subsubsection{Training and Skill Acquisition}

While accessibility often implies that a system should be intuitive and easily understood even by novice users, novel interfaces such as nonspeech auditory displays may require at least some minimal explanation or instruction for the user. Watson and Kidd (1994) accurately pointed out that many people will be unwilling to commit to extensive training in the meaning of sounds in an interface, yet brief training (i.e., under 30 minutes) has been shown to positively impact performance with auditory displays. Smith and Walker (2005) showed that brief training for a point estimation task resulted in better performance than no training. Walker and Nees (2005b) also demonstrated that a brief training period reduced performance error by $50 \%$ on a point estimation sonification task. Although to date, little attention has been paid to the issue of training sonification users, recent and ongoing work is examining exactly what types of training methods are most effective for different classes of sonifications (e.g., Walker and Nees, 2005a). Studies that have explicitly analyzed performance data over time (i.e., across trials or blocks of trials) have suggested that performance improves with experience with the 
novel displays (Walker and Lindsay, 2006b; Nees and Walker, 2008; Bonebright and Nees, in press), but the upper limits of performance with auditory displays remain unknown (Walker and Nees, 2005a; Nees and Walker, 2007). Longitudinal studies of skill acquisition with auditory interfaces are needed.

\subsubsection{Concurrent Sounds}

Numerous studies have shown that the discriminability and identifiability of sounds decrease as the number of concurrently presented sounds increase (Bonebright et al., 2001; Ericson, Brungart, and Simpson, 2003; McGookin and Brewster, 2004; Walker and Lindsay, 2006a; Lacherez, Seah, and Sanderson, 2007). Theory and research alike suggest, however, that such problems can be somewhat ameliorated to the extent that acoustic cues allow for concurrently presented sounds to be parsed into separate streams (Bregman, 1990). To this end, researchers have suggested that spatial separation of different data (e.g. presenting different data series to left and right headphone channels; see Bonebright et al., 2001; Brown et al., 2003), the use of distinct timbres for different data series (Bonebright et al., 2001; McGookin and Brewster, 2004), and staggering the onsets of concurrent messages (McGookin and Brewster, 2004) may all facilitate the segregation of concurrent audio information. While pitch is also an effective cue for parsing concurrent auditory streams, it is often used to represent dynamic, noncategorical information in auditory displays and may not be an appropriate dimension for promoting the separation of different data series. It should further be noted that the concurrent presentation of distinct channels of auditory information probably has a limit, beyond which the distinct streams of information will become impractical to parse and perceive (Flowers, 2005). This theoretical limit is likely dependent upon not only the number of concurrently presented sounds, but also upon their qualitative characteristics. Bonebright and Nees (in press), for example, found little to no interference for the comprehension of speech passages in the presence of a concurrent orienting task with earcons. Care should be taken when interfaces or environmental circumstances allow for overlapping sounds, as more research is needed to clarify the limits of perception for simultaneous auditory input.

\subsubsection{Delivery of Audio: Hardware}

A growing majority of digital devices come equipped with highfidelity sound production capabilities off-the-shelf. The auditory component of many interfaces may require little or no modification to hardware, but rather a design philosophy that takes better advantage of the existing capability to improve system accessibility with audio. The hardware considerations for the delivery of an audio interface may vary across different use scenarios, however, and Walker and Lindsay (2005) described a number of the challenges encountered when designing their system for wearable audio navigation (SWAN). The SWAN project encountered logistical constraints beyond the auditory interface itself, including technical limitations such as unreliability in sensors (e.g., the fallibility of GPS and other technologies that attempt to precisely determine a mobile user's location) as well as practical limitations in battery power, size, and durability of a wearable, mobile computer (also see Chapter 11, "Handheld Devices and Mobile Phones," in this volume).

Similarly, many attempts at auditory interfaces have been coupled with custom input devices (e.g., Morley et al., 1999; Winberg and Hellstrom, 2003), but such improvisations may not be necessary to the success of an auditory interface. While novel or emerging hardware technologies may eventually transform many of the ways in which people interact with a system (see Chapter 29, "Virtual Mouse and Keyboard for Text Entry," and Chapter 33, "Haptic Interaction," in this volume), existing, off-the-shelf capabilities of most hardware already allows for the implementation of auditory interfaces that could offer enhanced accessibility for many users.

For delivering sound, audio-capable systems have traditionally relied upon speakers or headphones, both of which are inexpensive options for producing audio of sufficient fidelity for most applications of auditory displays. Privacy and the potentially intrusive nature of delivering sounds through speakers are interrelated, basic concerns. When used in the presence of other people, speakers not only may compromise a user's privacy, but also can interfere with the activities of those nearby or cause annoyance. Headphones may circumvent these problems, but having one's ears covered by headphones introduces new difficulties for interacting with and maintaining awareness of one's surroundings. Blind users, for instance, gather a majority of their environmental information from sound, and they will generally be unwilling to cover their ears, even to use a potentially beneficial system.

One potential solution that is actively being researched is bonephones-bone-conduction headphones. Small transducers sit on the mastoid behind the ear and vibrate the skull, effectively stimulating the cochlea directly and bypassing the outer and middle ear. The ears remain uncovered, but the delivery of private audio messages is still possible. With minimal equalization, bonephones have been shown to have similar psychoacoustic signatures as headphones with regard to thresholds (Walker and Stanley, 2005), and early research suggests that virtual spatialized audio is possible with bonephones (Stanley and Walker, 2006). The devices, however, are currently not widely available to consumers, and more research is needed to clarify the potential role for interference between audio delivered via bonephones and concurrent stimulation from environmental sound sources.

\subsubsection{Delivery of Audio: Software}

As described throughout this chapter, most digital devices have off-the-shelf hardware and software capabilities for sound production, and the success of auditory interfaces will primarily be a function of empirically based design philosophies that embrace the use of sound. No standard add-on software packages exist for the general production of custom nonspeech audio 
for use in interfaces. Many laboratories involved in research on auditory displays, however, have developed purpose-specific sonification software packages that are often available as free, open-source downloads. Applications for representing data with sound include NASA's Mathtraxx ${ }^{4}$ the Oregon State University Science Access Project's Accessible Graphing Calculator, ${ }^{5}$ the Georgia Tech Sonification Lab's Sonification Sandbox ${ }^{6}$ (see Walker and Cothran, 2003; Davison and Walker, 2007) and Auditory Abacus ${ }^{7}$ (Walker, Lindsay, and Godfrey, 2004). Stockman, Hind, and Frauenberger (2005) are working on a prototype for a software package that works with Microsoft Excel and CSound to allow sonification of cells of spreadsheets, while Hetzler and Tardiff (2006) have also developed an Excel plug-in for data sonification. Cook (2007) recently described a number of software development projects aimed at analyzing and synthesizing environmental sounds. Other resources of interest for the auditory interface designer include the web site of the International Community for Auditory Display ${ }^{8}$ as well as the AUDITORY electronic mail list, ${ }^{9}$ both of which offer access to experts with years of collective experience in implementing sounds for research and application.

\subsection{Conclusions}

Sonification and auditory interfaces can enhance and improve the universal accessibility of a system for a number of users, tasks, and environments. The thoughtful and informed addition of nonspeech audio to an interface, especially as one important element of a holistic approach to universal design, can enhance and improve the accessibility and usability of a system. Nonspeech audio is uniquely suited to convey particular types of information and to ameliorate some of the limitations imposed by traditional visual interfaces. For the visually impaired, computers and other digital technologies have dramatically impacted and will continue to improve access to education, employment, and an overall higher quality of life (Gerber, 2003; Tobias, 2003), and nonspeech auditory displays can fill gaps in accessibility related to alerting or warning functions, status or process updates, ongoing monitoring tasks, and even data exploration. The relevance of nonspeech audio to interface design extends well beyond affordances for the visually impaired (e.g., Griffith, 1990). The benefits of universally usable interfaces should extend system capabilities for many users during visually intensive tasks or in environments where vision is not the ideal modality for information display. Auditory interfaces and sonification can be major contributors to compliance with at least five of the seven principles of universal design (Connell et al., 1997;

\footnotetext{
${ }^{4}$ http://prime.jsc.nasa.gov/mathtrax.

5 http://dots.physics.orst.edu/calculator.html.

${ }^{6}$ http://sonify.psych.gatech.edu/research/sonification_sandbox/index. html.

7 http://sonify.psych.gatech.edu/research/audio_abacus/index.html.

${ }^{8}$ http://www.icad.org.

${ }^{9}$ http://www.auditory.org.
}

McGuire et al., 2006), including (1) equitable use; (2) flexibility in use; (3) simple and intuitive use; (4) perceptible information; and (5) tolerance for error.

Flowers (2005) asked whether sound should be a standard component of desktop interfaces. This chapter has suggested that nonspeech sound is an under-used and under-investigated tool for the development of universally accessible interfaces. It further suggested that audio can be implemented immediately and cheaply in most existing interfaces, with little or no modifications to existing software and hardware. Ultimately, the potential of sound to benefit many users of an interface will only be unlocked when researchers commit to explore the bestpractice role of sound in interfaces and when designers actively implement audio in interfaces.

\section{References}

Anable, S. and Alonzo, A. (2001). Accessibility techniques for museum web sites, in the Proceedings of Museums and the Web (MW 2001), 14-17 March 2001, Seattle. http://www. archimuse.com/mw2001/papers/anable/anable.html.

Barrass, S. (1997). Auditory information design. PhD dissertation, Australian National University, Canberra, Australia.

Bigand, E. (1993). Contributions of music to research on human auditory cognition, in Thinking in Sound: The Cognitive Psychology of Human Audition (S. McAdams and E. Bigand, eds.), pp. 231-377. New York: Oxford University Press.

Blattner, M. M., Sumikawa, D. A., and Greenberg, R. M. (1989). Earcons and icons: Their structure and common design principles. Human-Computer Interaction 4: 11-44.

Bolia, R. S., D’Angelo, W. R., and McKinley, R. L. (1999). Aurally aided visual search in three-dimensional space. Human Factors 41: 664-669.

Boltz, M. G. (1998). Tempo discrimination of musical patterns: Effects due to pitch and rhythmic structure. Perception and Psychophysics 60: 1357-1373.

Bonebright,T.L.andNees,M.A.(2007a).Memoryforauditoryicons and earcons with localization cues, in the Proceedings of the International Conference on Auditory Display (ICAD2007), 26-29 June 2007, Montreal, Canada, pp. 419-422. http:// sonify.psych.gatech.edu/ mike/Nees\%20articles/ BonebrightNeesetal2001ICAD.pdf.

Bonebright, T. L. and Nees, M. A. (in press). Using an orienting auditory display during a concurrent listening task. Applied Cognitive Psychology.

Bonebright, T. L., Nees, M. A., Connerley, T. T., and McCain, G. R. (2001). Testing the effectiveness of sonified graphs for education: A programmatic research project, in the Proceedings of the International Conference on Auditory Display (ICAD2001), 29 July-1 August 2001, Helsinki, Finland, pp. 62-66.

Bregman, A. S. (1990). Auditory Scene Analysis: The Perceptual Organization of Sound. Cambridge, MA: MIT Press.

Brewster, S. (1997). Using non-speech sound to overcome information overload. Displays 17: 179-189. 
Brewster, S. (2002). Overcoming the lack of screen space on mobile computers. Personal and Ubiquitous Computing 6: 188-205.

Brewster, S., Wright, P. C., and Edward, D. E. (1994). The design and evaluation of an auditory enhanced scrollbar, in the Proceedings of the SIGCHI Conference on Human Factors in Computing Systems (CHI 94), 24-28 April 1994, Boston, pp. 173-179. New York: ACM Press.

Brewster, S., Wright, P. C., and Edwards, A. D. N. (1993). An evaluation of earcons for use in auditory human-computer interfaces, in the Proceedings of the SIGCHI Conference on Human Factors in Computing Systems (CHI 93), 24-29 April 1993, Amsterdam, The Netherlands, pp. 222-227. New York: ACM Press.

Brock, D., Stroup, J. L., and Ballas, J. A. (2002). Using an auditory display to manage attention in a dual task, multiscreen environment, in the Proceedings of the International Conference on Auditory Display (ICAD2002), 2-5 July 2002, Kyoto, Japan. http://www.cogsci.rpi.edu/cogworks/down/ BrockEtAl_ICAD02.pdf.

Brown, L. M. and Brewster, S. (2003). Drawing by ear: Interpreting sonified line graphs, in the Proceedings of the International Conference on Auditory Display (ICAD2003), 6-9 July 2003, Boston, pp. 152-156.

AQ3

Brown, L. M., Brewster, S., Ramloll, R., Burton, M., and Riedel, B. (2003). Design guidelines for audio presentation of graphs and tables, in the Proceedings of the International Conference on Auditory Display (ICAD2003), 6-9 July 2003, pp. 284-287.

Brown, L. M., Brewster, S., and Riedel, B. (2002). Browsing modes for exploring sonified line graphs, in the Proceedings of the 16th British HCI Conference, 2-6 September 2002, London, pp. 2-5. http://www.dcs.gla.ac.uk/ stephen/papers/HCI2002-brown. pdf.

Brown, M. L., Newsome, S. L., and Glinert, E. P. (1989). An experiment into the use of auditory cues to reduce visual workload, in the Proceedings of the ACM CHI 89 Human Factors in Computing Systems Conference (CHI 89), 30 April-4 May 1989, Austin, TX, pp. 339-346. New York: ACM Press.

Childs, E. (2005). Auditory graphs of real-time data, in the Proceedings of the International Conference on Auditory Display (ICAD2005), 6-9 July 2005, Limerick, Ireland. http:// sonify.psych.gatech.edu/ags2005/pdf/AGS05_Childs.pdf.

Connell, B. R., Jones, M., Mace, R., Mueller, J., Mullick, A., Ostroff, E., et al. (1997). The Principles of Universal Design, Version 2.0. Raleigh, NC: The Center for Universal Design.

Cook, P. R. (2007). Din of an "iquity": Analysis and synthesis of environmental sounds, in the Proceedings of the International Conference on Auditory Display (ICAD2007), 26-29 June 2007, Montreal, Canada, pp. 167-172.

AQ5

Davison, B. K. and Walker, B. N. (2007). Sonification Sandbox reconstruction: Software standard for auditory graphs, in the Proceedings of the International Conference on Auditory Display (ICAD2007), 26-29 June 2007, Montreal, Canada pp. 509-512.

de Campo, A. (2007). Toward a data sonification design space map, in the Proceedings of the International Conference on
Auditory Display (ICAD2007), 26-29 June 2007, Montreal, Canada, pp. 342-347.

Dombois, F. (2001). Using audification in planetary seismology, in the Proceedings of the International Conference on Auditory Display (ICAD2001), 29 July-1 August 2001, Helsinki, Finland, pp. 227-230.

Durlach, N. I., Mason, C. R., Kidd, G., Arbogast, T. L., Colburn, H. S., and Shinn-Cunningham, B. (2003). Note on informational masking. Journal of the Acoustical Society of America 113: 2984-2987.

Edwards, A. D. N. (1989a). Modelling blind users' interactions with an auditory computer interface. International Journal of Man-Machine Studies 30: 575-589.

Edwards, A. D. N. (1989b). Soundtrack: An auditory interface for blind users. Human-Computer Interaction 4: 45-66.

Edworthy, J. (1998). Does sound help us to work better with machines? A commentary on Rautenberg's paper "About the importance of auditory alarms during the operation of a plant simulator." Interacting with Computers 10: 401-409.

Edworthy, J. and Hellier, E. (2006). Complex nonverbal auditory signals and speech warnings, in Handbook of Warnings (M. S. Wogalter, ed.), pp. 199-220. Mahwah, NJ: Lawrence Erlbaum Associates.

Edworthy, J., Hellier, E. J., Aldrich, K., and Loxley, S. (2004). Designing trend-monitoring sounds for helicopters: Methodological issues and an application. Journal of Experimental Psychology: Applied 10: 203-218.

Eimer, M. (2001). Crossmodal links in spatial attention between vision, audition and touch: Evidence from event-related brain potentials. Neuropsychologia 39: 1292-1303.

Eiriksdottir, E., Nees, M. A., Lindsay, J., and Stanley, R. (2006). User preferences for auditory device-driven menu navigation, in the Proceedings of the Human Factors and Ergonomics Society 50th Annual Meeting, 16-20 October 2006, San Francisco, pp. 2076-2078.

Ericson, M. A., Brungart, D. S., and Simpson, B. D. (2003). Factors that influence intelligibility in multitalker speech displays. International Journal of Aviation Psychology 14: 313-334.

Flowers, J. H. (2005). Thirteen years of reflection on auditory graphing: Promises, pitfalls and potential new directions, in the Proceedings of the International Conference on Auditory Display (ICAD2005), 6-9 July 2005, Limerick, Ireland. http:// sonify.psych.gatech.edu/ags2005/pdf/AGS05_Flowers.pdf.

Flowers, J. H., Buhman, D. C., and Turnage, K. D. (1997). Crossmodal equivalence of visual and auditory scatterplots for exploring bivariate data samples. Human Factors 39: 341-351.

Flowers, J.H., Buhman, D. C., and Turnage, K. D. (2005). Data sonification from the desktop: Should sound be part of standard data analysis software? ACM Transactions on Applied Perception 2: 467-472.

Flowers, J. H. and Hauer, T. A. (1992). The ear's versus the eye's potential to assess characteristics of numeric data: Are we too visuocentric? Behavior Research Methods, Instruments and Computers 24: 258-264. 
Flowers, J. H. and Hauer, T. A. (1993). "Sound" alternatives to visual graphics for exploratory data analysis. Behavior Research Methods, Instruments and Computers 25: 242-249.

Flowers, J.H. and Hauer, T. A. (1995). Musical versus visual graphs: Cross-modal equivalence in perception of time series data. Human Factors 37: 553-569.

Folds, D. J. (2006). The elevation illusion in virtual audio, in the Proceedings of the Human Factors and Ergonomics Society 50th Annual Meeting, 16-20 October 2006, San Francisco, pp. 1576-1580.

Franklin, K. M. and Roberts, J. C. (2004). A path based model for sonification, in the Proceedings of the Eighth International Conference on Information Visualization (IV'04), 14-16 July 2004, London, pp. 865-870.

Frauenberger, C., Stockman, T., and Bourguet, M.-L. (2007a). A survey on common practice in designing audio user interface, in the Proceedings of the 21st British HCI Group Annual Conference (HCI 2007), Volume 1, 22-27 July 2007, Beijing, pp. 187-195.

Frauenberger, C., Stockman, T., and Bourguet, M.-L. (2007b). Pattern design in the context space: A methodological framework for auditory display design, in the Proceedings of the International Conference on Auditory Display (ICAD2007), 26-29 June 2007, Montreal, Canada, pp. 513-518.

Frysinger, S. P. (2005). A brief history of auditory data representation to the 1980s, in the Proceedings of the International Conference on Auditory Display (ICAD2005), 6-9 July 2005, Limerick, Ireland. http://sonify.psych.gatech.edu/ags2005/ pdf/AGS05_Frysinger.pdf.

Gaver,W.W. (1989). The SonicFinder: An interface that uses auditory icons. Human-Computer Interaction 4: 67-94.

Gaver,W.W., Smith, R. B., and O'Shea, T. (1991).Effective sounds in complex systems: The ARKola simulation, in the Proceedings of the ACM Conference on Human Factors in Computing Systems (CHI 91), 28 April-5 May 1991, New Orleans, pp. 85-90. New York: ACM Press.

Gerber, E. (2003). The benefits of and barriers to computer use for individuals who are visually impaired. Journal of Visual Impairment and Blindness 97: 536-550.

Golledge, R. G., Loomis, J. M., Klatzky, R. L., Flury, A., and Yang, X. L. (1991). Designing a personal guidance system to aid navigation without sight: Progress on the GIS component. International Journal of Geographical Information Systems 5: 373-395.

Griffith, D. (1990). Computer access for persons who are blind or visually impaired: Human factors issues. Human Factors 32: 467-475.

Grudin, J. (2001). Partitioning digital worlds: Focal and peripheral awareness in multiple monitor use, in the Proceedings of the 2001 SIGCHI Conference on Human Factors in Computing Systems (CHI 01), 31 March-5 April 2001, Seattle, pp. 458465. New York: ACM Press.

Haas, E. C. and Edworthy, J. (1996). Designing urgency into auditory warnings using pitch, speed and loudness. Computing and Control Engineering Journal 7: 193-198.
Hartmann, W. M. (1997). Sounds, Signals and Sensation: Modern Acoustics and Signal Processing. New York: Springer-Verlag.

Hereford, J. and Winn, W. (1994). Non-speech sound in humancomputer interaction: A review and design guidelines. Journal of Educational Computer Research 11: 211-233.

Hermann, T. and Hunt, A. (2005). An introduction to interactive sonification. IEEE Multimedia 12: 20-24.

Hetzler, S. M. and Tardiff, R. M. (2006). Two tools for integrating sonification into calculus instruction, in the Proceedings of the International Conference on Auditory Display (ICAD2006), 19-24 June 2006, London, pp. 281-284.

International Conference on Auditory Display (2004). Listening to the mind listening: Concert of sonifications at the Sydney Opera House, from the Proceedings of the International Conference on Auditory Display (ICAD2004), 6-9 July 2004, Sydney, Australia [Concert].

International Conference on Auditory Display (2006). Global music: The world by ear, from the Proceedings of the International Conference on Auditory Display (ICAD2006), 19-24 June 2006, London [Concert].

Jeon, J. Y. and Fricke, F. R. (1997). Duration of perceived and performed sounds. Psychology of Music 25: 70-83.

Keller, P. and Stevens, C. (2004). Meaning from environmental sounds: Types of signal-referent relations and their effect on recognizing auditory icons. Journal of Experimental Psychology: Applied 10: 3-12.

Kramer, G. (1994). An introduction to auditory display, in Auditory Display: Sonification, Audification and Auditory Interfaces (G. Kramer, ed.), pp. 1-78. Reading, MA: Addison-Wesley.

Kramer, G., Walker, B. N., Bonebright, T., Cook, P., Flowers, J., Miner, N., et al. (1999). The Sonification Report: Status of the Field and Research Agenda. Report Prepared for the National Science Foundation by Members of the International Community for Auditory Display. Santa Fe, NM: International Community for Auditory Display (ICAD).

Lacherez, P., Seah, E. L., and Sanderson, P. M. (2007). Overlapping melodic alarms are almost indiscriminable. Human Factors 49: 637-645.

Liljedahl, M., Papworth, N., and Lindberg, S. (2007). Beowulf: A game experience built on sound effects, in the Proceedings of the International Conference on Auditory Display (ICAD2007), 26-29 June 2007, Montreal, Canada, pp. 102-106.

Loomis, J. M., Golledge, R. G., and Klatzky, R. L. (1993). Personal guidance system for the visually impaired using GPS, GIS and VR technologies, in the Proceedings of the First Annual International Conference, Virtual Reality and Persons with Disabilities, 17-18 June 1993, Millbrae, CA, pp. 71-74.

Loomis, J. M., Marston, J. R., Golledge, R. G., and Klatzky, R. L. (2005). Personal guidance system for people with visual impairment: A comparison of spatial displays for route guidance. Journal of Visual Impairment and Blindness 99: 219-232.

Mankoff, J., Fait, H., and Tran, T. (2005). Is your web page accessible? A comparative study of methods for assessing web page 
accessibility for the blind, in the Proceedings of the ACM CHI Conference on Human Factors Computing Systems (CHI 05), 2-7 April 2005, Portland, OR, pp. 41-50. New York: ACM Press.

Mauney, B. S. and Walker, B. N. (2004). Creating functional and livable soundscapes for peripheral monitoring of dynamic data, in the Proceedings of the International Conference on Auditory Display (ICAD2004), 6-10 July 2004, Sydney, Australia. http://www.icad.org/websiteV2.0/Conferences/ ICAD2004/papers/mauney_walker.pdf.

Mauney, L. M. (2006). Individual Differences in Cognitive, Musical and Perceptual Abilities. Master's thesis, Georgia Institute of Technology, Atlanta. http://smartech.gatech.edu/bitstream/ 1853/13972/1/mauney_lisa_m_200612_mast.pdf.

McDonald, J. J., Teder-Salejarvi, W. A., and Hillyard, S. A. (2000). Involuntary orienting to sound improves visual perception. Nature 407: 906-908.

McGookin, D. K. and Brewster, S. (2004). Understanding concurrent earcons: Applying auditory scene analysis principles to concurrent earcon recognition. ACM Transactions on Applied Perception 1: 130-150.

McGuire, J. M., Scott, S. S., and Shaw, S. F. (2006). Universal design and its applications in educational environments. Remedial and Special Education 27: 166-175.

Meyer, A. and Rose, D. H. (2000). Universal design for individual differences. Educational Leadership 58: 39-43.

Mondor, T. A. and Amirault, K. (1998). Effect of same- and different-modality spatial cues on auditory and visual target identification. Journal of Experimental Psychology: Human Perception and Performance 24: 745-755.

Morley, S., Petrie, H., O’Neill, A.-M., and McNally, P. (1999). Auditory navigation in hyperspace: Design and evaluation of a non-visual hypermedia system for blind users. Behaviour and Information Technology 18: 18-26.

Mynatt, E. D. (1997). Transforming graphical interfaces into auditory interfaces for blind users. Human-Computer Interaction 12: 7-45.

Mynatt, E. D. and Edwards, W. K. (1992). Mapping GUIs to auditory interfaces, in the Proceedings of the 5th Annual ACM Symposium on User Interface Software and Technology, 15-18 November 1992, Monterrey, CA, pp. 61-79.

AQ10

Nees, M. A. and Walker, B. N. (2007). Listener, task and auditory graph: Toward a conceptual model of auditory graph comprehension, in the Proceedings of the International Conference on Auditory Display (ICAD2007), 26-29 June 2007, Montreal, Canada, pp. 266-273. http://sonify.psych. gatech.edu/ walkerb/publications/pdfs/2007ICADNeesWalker.pdf.

Nees, M. A. and Walker, B. N. (2008). Data density and trend reversals in auditory graphs: Effects on point estimation and trend identification tasks. ACM Transactions on Applied Perception 5.

AQ11

Neuhoff, J. G., Kramer, G., and Wayand, J. (2002). Pitch and loudness interact in auditory displays: Can the data get lost in the map? Journal of Experimental Psychology: Applied 8: 17-25.
Palladino, D. and Walker, B. N. (2007). Learning rates for auditory menus enhanced with spearcons versus earcons, in the Proceedings of the International Conference on Auditory Display (ICAD2007), 26-29 June 2007, Montreal, Canada, pp. 274-279. http://sonify.psych.gatech.edu/ walkerb/ publications/pdfs/2007ICAD-PalladinoWalker.pdf.

Peres, S. C. and Lane, D. M. (2003). Sonification of statistical graphs, in the Proceedings of the International Conference on Auditory Display (ICAD2003), 6-9 July 2003, Boston, pp. 157-160.

Peres, S. C. and Lane, D. M. (2005). Auditory graphs: The effects of redundant dimensions and divided attention, in the Proceedings of the International Conference on Auditory Display (ICAD2005), 6-9 July 2005, Limerick, Ireland, pp. 169-174.

Quinn, M. and Meeker, L. D. (2001). Research set to music: The climate symphony and other sonifications of ice core, radar, DNA, seismic and solar wind data, in the Proceedings of the International Conference on Auditory Display (ICAD2001), 29 July-1 August 2001, Helsinki, Finland. http://www.acoustics.hut.fi/icad2001/proceedings/papers/quinn.pdf.

Ramloll, R., Brewster, S., Yu, W., and Riedel, B. (2001). Using non-speech audio sounds to improve access to $2 \mathrm{D}$ tabular numerical information for visually impaired uses, in the Proceedings of the IHM-HCI 2001, 10-14 September 2001, Lille, France, pp. 515-530.

Resnikoff, S., Pascolini, D., Etya'ale, D., Kocur, I., Pararajasegaram, R., Pokharel, G. P., et al. (2004). Global data on visual impairment in the year 2002. Bulletin of the World Health Organization 82: 844-851.

Roth, P., Kamel, H., Petrucci, L., and Pun, T. (2002). A comparison of three nonvisual methods for presenting scientific graphs. Journal of Visual Impairment and Blindness 96: 420-428.

Salmen, J. P. (1998). Everyone's Welcome: The Americans with Disabilities Act and Museums. Washington, DC: American Association of Museums.

Sandor, A. and Lane, D. M. (2003). Sonification of absolute values with single and multiple dimensions, in the Proceedings of the International Conference on Auditory Display (ICAD2003), 6-9 July 2003, Boston, pp. 243-246.

Schmitt, M., Postma, A., and De Haan, E. (2000). Interactions between exogenous auditory and visual spatial attention. Quarterly Journal of Experimental Psychology 53A: 105-130.

Smith, D. R. and Walker, B. N. (2005). Effects of auditory context cues and training on performance of a point estimation sonification task. Applied Cognitive Psychology 19: 1065-1087.

Spence, C. and Driver, J. (1997). Audiovisual links in attention: Implications for interface design, in Engineering Psychology and Cognitive Ergonomics Vol. 2: Job Design and Product Design (D. Harris, ed.), pp. 185-192. Hampshire, U.K.: Ashgate Publishing.

Spence, C., McDonald, J. J., and Driver, J. (2004). Exogenous spatial-cuing studies of human cross-modal attention and multisensory integration, in Cross-Modal Space and
$\mathrm{AQ12}$

AQ13 
Cross-Modal Attention (C. Spence and J. Driver, eds.), pp. 277-320. Oxford, U.K.: Oxford University Press.

Stanley, R. and Walker, B. N. (2006). Lateralization of sounds using bone-conduction headsets, in the Proceedings of the Annual Meeting of the Human Factors and Ergonomics Society (HFES 2006), 16-20 October 2006, San Francisco, pp. 1571-1575. http://sonify.psych.gatech.edu/ walkerb/publications/ pdfs/2006HFES-StanleyWalker.pdf.

Stevens, S. S. (1936). A scale for the measurement of a psychological magnitude: Loudness. Psychological Review 43: 405-416.

Stevens, S. S., Volkmann, J., and Newman, E. B. (1937). A scale for the measurement of the psychological magnitude pitch. The Journal of the Acoustical Society of America 8: 185.

Stockman, T., Hind, G., and Frauenberger, C. (2005). Interactive sonification of spreadsheets, in the Proceedings of the International Conference on Auditory Display (ICAD2005), 6-9 July 2005, Limerick, Ireland, pp. 134-139.

Stockman, T., Rajgor, N., Metatla, O., and Harrar, L. (2007). The design of interactive audio soccer, in the Proceedings of the International Conference on Auditory Display (ICAD2007), 26-29 June 2007, Montreal, Canada, pp. 526-529.

Targett, S. and Fernstrom, M. (2003). Audio games: Fun for all? All for fun? in the Proceedings of the International Conference on Auditory Display (ICAD2003), 6-9 July 2003, Boston, pp. 216-219.

Tobias, J. (2003). Information technology and universal design: An agenda for accessible technology. Journal of Visual Impairment and Blindness 97: 592-601.

Turnbull, W.W. (1944). Pitch discrimination as a function of tonal duration. Journal of Experimental Psychology 34: 302-316.

Walker, B. N. (2002). Magnitude estimation of conceptual data dimensions for use in sonification. Journal of Experimental Psychology: Applied 8: 211-221.

Walker, B. N. (2007). Consistency of magnitude estimations with conceptual data dimensions used for sonification. Applied Cognitive Psychology 21: 579-599.

Walker, B. N. and Cothran, J. T. (2003). Sonification Sandbox: A graphical toolkit for auditory graphs, in the Proceedings of the International Conference on Auditory Display (ICAD2003), 6-9 July 2003, Boston, pp. 161-163. http://sonify.psych. gatech.edu/ walkerb/publications/pdfs/2003ICADWalkerCothran-Sandbox.pdf.

Walker, B. N., Godfrey, M. T., Orlosky, J. E., Bruce, C., and Sanford, J. (2006). Aquarium sonification: Soundscapes for accessible dynamic informal learning environments, in the Proceedings of the International Conference on Auditory Display (ICAD2006), 15-20 July 2006, Madrid, pp. 238-241. http://sonify.psych.gatech.edu/ walkerb/publications/ pdfs/2006ICAD-WalkerGodfreyOrloskyBruceSanford.pdf.

Walker, B. N., Kim, J., and Pendse, A. (2007). Musical soundscapes for an accessible aquarium: Bringing dynamic exhibits to the visually impaired, in the Proceedings of the International Computer Music Conference (ICMC 2007), 27-31 August 2007, Copenhagen, Denmark, pp. 268-275. http://sonify. psych.gatech.edu/ walkerb/publications/pdfs/2007ICMCWalkerKimPendse.pdf.

Walker, B. N. and Kramer, G. (1996). Human factors and the acoustic ecology: Considerations for multimedia audio design, in the Proceedings of the Audio Engineering Society 101st Convention, 8-11 November 1996, Los Angeles. http://sonify.psych.gatech.edu/ walkerb/publications/ pdfs/1996AES-HF_ecology.pdf.

Walker, B. N. and Kramer, G. (2004). Ecological psychoacoustics and auditory displays: Hearing, grouping and meaning making, in Ecological Psychoacoustics (J. Neuhoff, ed.), pp. 150-175. New York: Academic Press.

Walker, B. N. and Kramer, G. (2005). Mappings and metaphors in auditory displays: An experimental assessment. ACM Transactions on Applied Perception 2: 407-412.

Walker, B. N. and Kramer, G. (2006a). Auditory displays, alarms and auditory interfaces, in International Encyclopedia of Ergonomics and Human Factors (2nd ed.) (W. Karwowski, ed.), pp. 1021-1025. New York: CRC Press.

Walker, B. N. and Kramer, G. (2006b). Sonification, in International Encyclopedia of Ergonomics and Human Factors (2nd ed.) (W. Karwowski, ed.), pp. 1254-1256. New York: CRC Press.

Walker, B. N. and Lane, D. M. (2001). Psychophysical scaling of sonification mappings: A comparison of visually impaired and sighted listeners, in the Proceedings of the International Conference on Auditory Display (ICAD2001), 29 July-1 August 2001, Helsinki, Finland, pp. 90-94. http://sonify. psych.gatech.edu/ walkerb/publications/pdfs/2001ICADWalkerLane-Paper.pdf.

Walker, B. N. and Lindsay, J. (2005). Using virtual environments to prototype auditory navigation displays. Assistive Technology 17: $72-81$.

Walker, B. N. and Lindsay, J. (2006a). The effect of a speech discrimination task on navigation in a virtual environment, in the Proceedings of the Human Factors and Ergonomics Society 50th Annual Meeting, 16-20 October 2006, Santa Monica, CA, pp. 1538-1541. http://sonify.psych.gatech.edu/ walkerb/ publications/pdfs/2006HFES-WalkerLindsay.pdf.

Walker, B.N. and Lindsay, J. (2006b). Navigation performance with a virtual auditory display: Effects of beacon sound, capture radius and practice. Human Factors 48: 265-278.

Walker, B. N., Lindsay, J., and Godfrey, J. (2004). The Audio abacus: Representing a wide range of values with accuracy and precision, in the Proceedings of the International Conference on Auditory Display (ICAD2004), 6-9 July 2004, Sydney, Australia. http://www.icad.org/websiteV2.0/Conferences/ ICAD2004/papers/walker_lindsay_godfrey.pdf.

Walker, B. N. and Mauney, L. M. (2004). Individual differences, cognitive abilities and the interpretation of auditory graphs, in the Proceedings of the International Conference on Auditory Display (ICAD2004), 6-9 July 2004, Sydney, Australia. http://sonify.psych.gatech.edu/ walkerb/publications/pdfs/2004ICAD-WalkerLMauney.pdf.

Walker, B. N., Nance, A., and Lindsay, J. (2006). Spearcons: Speechbased earcons improve navigation performance in auditory 
menus, in the Proceedings of the International Conference on Auditory Display (ICAD2006), 15-20 July 2006, Madrid, pp. 95-98. http://sonify.psych.gatech.edu/ walkerb/publications/pdfs/2006ICAD-WalkerNanceLindsay.pdf.

Walker, B. N. and Nees, M. A. (2005a). An agenda for research and development of multimodal graphs, in the Proceedings of the International Conference on Auditory Display (ICAD2005), 6-9 July 2005, Limerick, Ireland, pp. 428-432. http://sonify.psych.gatech.edu/ walkerb/publications/ pdfs/2005ICADAGS-WalkerNees.pdf.

Walker, B. N. and Nees, M. A. (2005b). Brief training for performance of a point estimation sonification task, in the Proceedings of the International Conference on Auditory Display (ICAD2005), 6-9 July 2005, Limerick, Ireland, pp. 276-279. http://sonify.psych.gatech.edu/ walkerb/publications/pdfs/2005ICAD-WalkerNees-training.pdf.

Walker, B. N. and Nees, M. A. (in press). Theory of sonification, in Principles of Sonification: An Introduction to Auditory Display (T. Hermann, A. Hunt, and J. Neuhoff, eds.).

Walker, B. N. and Stanley, R. (2005). Thresholds of audibility for bone-conduction headsets, in the Proceedings of the International Conference on Auditory Display (ICAD2005), 6-9 July 2005, Limerick, Ireland, pp. 218-222.

Watson, C. S. and Kidd, G. R. (1994). Factors in the design of effective auditory displays, in the Proceedings of the International
Conference on Auditory Display (ICAD1994), 7-9 November 1994, Santa Fe, NM.

Wightman, F. L. and Kistler, D. J. (1983). Headphone simulation of free-field listening I: Stimulus synthesis. Journal of the Acoustical Society of America 85: 858-867.

Wightman, F. L. and Kistler, D. J. (1989). Headphone simulation of free-field listening II: Psychophysical validation. Journal of the Acoustical Society of America 85: 868-878.

Wilson, J., Walker, B. N., Lindsay, J., Cambias, C., and Dellaert, F. (2007). SWAN: System for wearable audio navigation, in the Proceedings of the 11th International Symposium on Wearable Computers (ISWC 2007), 11-15 November 2007, Busan, Korea, pp. 91-98.

Winberg, F. and Hellstrom, S. O. (2001). Qualitative aspects of auditory direct manipulation: A case study of the Towers of Hanoi, in the Proceedings of the International Conference on Auditory Display (ICAD2001), 29 July-1 August 2001, Helsinki, Finland, pp. 16-20.

Winberg, F. and Hellstrom, S. O. (2003). Designing accessible auditory drag and drop, in the Proceedings of the 2003 Conference on Universal Usability (CUU2003), 10-11 November 2003, Vancouver, Canada, pp. 152-153.

Yalla, P. and Walker, B.N. (2007). Advanced Auditory Menus. Georgia Institute of Technology GVU Center Technical Report \# GIT-GVU-07-12. Atlanta: Georgia Institute of Technology. 


\section{Author Queries}

AQ1: Please provide updated publication information for Bonebright and Nees (in press), if possible.

AQ2: Please provide publisher and publisher location for Bonebright et al. (2001).

AQ3: Please provide publisher and publisher location for Brown and Brewster (2003).

AQ4: Please provide publisher and publisher location for Brown et al. (2003).

AQ5: Please provide publisher and publisher location for Cook (2007), Davison and Walker (2007), de Campo (2007), and

Dombois (2001).

AQ6: Please provide publisher and publisher location for Eiriksdottir et al. (2006).

AQ7: Please provide publisher and publisher location for Folds (2006), Franklin and Roberts (2004), and Frauenberger et al. (2007a and 2007b).

AQ8: Can you provide additional publication information for International Conference on Auditory Display (2004 and 2006)? Are these available as CDs? Are there URLs for MP3s? etc.

AQ9: Please provide publisher and publisher location for Liljedahl et al. (2007) and Loomis et al. (1993).

AQ10: Please provide publisher and publisher location for Mynatt and Edwards (1992).

AQ11: Please provide page range for Nees and Walker (2008).

AQ12: Please provide publisher and publisher location for Peres and Lane (2003 and 2005).

AQ13: Please provide publisher and publisher location for Ramloll et al. (2001).

AQ14: Please provide publisher and publisher location for Sandor and Lane (2003).

AQ15: Please provide publisher and publisher location for Stockman et al. (2005 and 2007) and Targett and Fernstrom (2003).

AQ16: Please provide publisher and publisher location for Walker and Nees (in press), if available.

AQ17: Please provide publisher and publisher location for Walker and Stanley (2005).

AQ18: Please provide page range, publisher, and publisher location for Watson and Kidd (1994).

AQ19: Please provide publisher and publisher location for Wilson et al. (2007) and Winberg and Hellstrom (2001 and 2003). 